\title{
LA FILOSOFÍA MÍSTICA DE RUSSELL Y LO INDECIBLE EN EL TRACTATUS
}

ALEJANDRO TOMASINI BASSOLS

INSTTTUTO DE INVESTIGACIONES FiLOSÓFICAS Universidad Nacional Autónoma de México

Las filosofías de Russell y Wittgenstein han sido examinadas conjuntamente, comparadas y evaluadas en numerosas ocasiones. No obstante, la casi totalidad de las veces en que se han efectuado estudios comparativos, en especial de sus atomismos lógicos, los temas que se han abordado son de lógica filosófica, de metafisica, de filosofia de la mente, de filosofía de las matemáticas, etc. No deja de ser un tanto curioso, por lo tanto, el que aquello que por lo menos para Wittgenstein constituía la motivación profunda de su pensamiento, el objetivo último de comprensión, esto es, los temas "abordados" y sugeridos al final del Tractatus, no hayan sido considerados por los filósofos como dignos de atención para una confrontación seria con Russell. Después de todo, ellos no sólo se ocuparon de las proposiciones atómicas y las constantes lógicas. El hecho de que a este respecto haya más bien pocos estudios comparativos podría deberse, empero, a que se pensara que sobre estos temas Russell no tenía nada que decir. Yo considero que opinar así sería cometer un inmenso error. En este trabajo, por consiguiente, me propongo presentar, comparar y discutir precisamente algunos de los puntos de vista que sobre lo que por el momento acotaremos mediante la expresión 'los temas importantes' y que Russell y Wittgenstein mantuvieron durante el perído clásico del atomismo lógico. Mi presentación de la posición de Russell es una construcción porque, a diferencia de lo que sucede con Wittgenstein, el material relevante se halla diseminado en diversos textos. Como era de esperarse, hay puntos de vista comunes y hay, asimismo, diversas cuestiones enfocadas ya sea por uno ya sea por el otro. Trataré de evitar conflictos, pero cuando ellos resulte imposible tomaré partido por la concepción que me parezca más convincente.

En relación con Wittgenstein, nuestra primera sorpresa se produce cuando nos percatamos de que, considerada globalmente, su posición es paradójica, pues la doctrina misma del lenguaje y la metafísica que quizá habían sido elaboradas para permitirnos descubrir verdades acerca de lo que constituye nuestro actual objeto de estudio nos impiden decir cualquier cosa acerca de 
él! Nosotros sentimos una intensa necesidad de ir más allá de lo que permiten la ciencia y el lenguaje estrictamente descriptivo, pero nos encontramos con que, aunque nuestras aclaraciones sobre el lenguaje y la ciencia justifican la sensación de que lo que decimos no basta, ellas mismas nos impiden ir más allá y rebasar los estrechos límites de la significatividad real. ¿Cómo puede suceder algo así? Para responder a esta pregunta, haremos un veloz recorrido por los dominios de la Teoría Pictórica.

Las ideas centrales de la "doctrina" wittgensteiniana del lenguaje, aunque sutiles y de complejas ramificaciones, son relativamente simples y de fácil aprehensión. Se nos indica, por ejemplo, que las proposiciones, que también son hechos, son la clase de cosas que pueden representar a otro hecho, es decir, son figuras de los hechos y figuras que son pensadas como representándolos. Dado que toda proposición analizada es una concatenación de nombres, es decir, de signos simples, las proposiciones son necesariamente complejas. Tres son por lo menos las condiciones que las proposiciones deben satisfacer: deben tener la misma estructura que los hechos que representan, deben poseer su misma multiplicidad lógica y, también, deben tener algo en común con ellos. Lo que comparten es la forma lógica. Los elementos de la proposición son los nombres de los elementos de los hechos representados. Gracias a ellos, la proposición está "vinculada a la realidad" y será verdadera o falsa en virtud de su acuerdo o desacuerdo con el mundo. Es importante evitar identificar a la forma lógica o forma de la realidad con lo que Wittgenstein llama la 'forma pictórica'. Las figuras tienen una cierta estructura y la forma pictórica es la posibilidad de esa estructura. De este modo, la forma pictórica atañe a los elementos (nombres u objetos) y sus posibilidades, en tanto que la forma lógica concierne a las proposiciones y a los hechos. Diversas figuras pueden tener diferentes formas pictóricas, pero todas las figuras posibles tienen la misma forma lógica. Una figura representa su sentido y su sentido no es ni un valor de verdad ni un Gedanke fregeano sino un hecho o, más bien, una situación posible en el espacio lógico.

Lo que acabamos de exponer pertenece al núcleo formal de la teoría wittgensteiniana de la representación, pero es claro que Wittgenstein debe darnos también una explicación de lo que sucede cuando una figura es de hecho pensada. Para convertirse en algo vivo, la figura debe estar relacionada con su hecho mediante algún "método de proyección". Ahora bien, aunque son posibles muchos métodos de proyección sólo uno es, en el sentido más estricto de la expresión, lógicamente correcto. Este corresponde al caso en el que los nombres de la proposición son signos lógicamente simples, signos cuyos significados son los objetos denotados. En este caso entonces puede afirmarse que una proposición es pensada cuando sus nombres son usados. De este modo, Wittgenstein funde dos teorías: la teoría pictórica del sentido para las proposiciones y la teoría denotativa del significado para los nombres. 
La única restricción (muy importante) que impone sobre esta última es que a los nombres se les considerará como significativos sólo en el contexto de una proposición. Considerados aisladamente, los nombres no tienẹn significado o, lo que probablemente sea un reporte más preciso, sencillamente no hay nombres aislados. A su vez, la teoría de los nombres surge de dos "tesis": la tesis de que el análisis es posible y la tesis de que el sentido de las proposiciones debe estar determinado (o sea, no puede ser algo mutable o inestable o sin límites definidos).

$\mathrm{Y}$ es aquí precisamente que emerge una sorprendente doctrina. La Teoría Pictórica describe las condiciones necesarias que tendría que satisfacer cualquier lenguaje, es decir, tanto un lenguaje descriptivo perfecto como los imperfecto lenguajes naturales que conocemos. Ella indica, por consiguiente, qué combinaciones de símbolos tanto en ese lenguaje ideal o paradigmático como en cualquier otro serían significativas y cuáles no. En otras palabras, la teoría fija los límites de lo que es decible pero - y esto es de vital importancia- pretende fijarlos desde dentro del lenguaje, es decir, sin traspasar esos límites. Así, aunque tuviéramos a nuestra disposición un lenguaje idealmente preciso, de todos modos estaríamos incapacitados para describir lo que "sucede" "más alla"" de sus límites, si bien el mero hecho de haber establecido límites muestra que hay algo "afuera" de ellos. El problema es que manifestamos una fuerte inclinación por ir más allá de esos límites, que no son sino los límites de la signifitavidad y la factualidad, a pesar de saber que desde un punto de vista lógico siempre que lo intentemos lo que estaremos haciendo será emitir sinsentidos. Wittgenstein parece pensar, no obstante, que hay un modo indirecto de eludir los obstáculos objetivos inherentes al lenguaje e impuestos por la sintáxis lógica. Eso que quisiéramos decir y que no podemos decir tiene una manifestación peculiar: se muestra en el uso del simbolismo. Ahora bien, la aprehensión de lo indecible indica eo ipso a quien comprendió la lógica de nuestro lenguaje que eso que "aprehendió" no se puede expresar y que, en algún sentido, no tiene derecho a intentar decir nada al respecto. Bouveresse ha puesto en claro esto como sigue: “Pero la solución negativa tiene, en Wittgenstein, un contenido netamente positivo: el universo de las respuestas posibles, el de lo decible, 'hace señales' hacia algo, fuera de sus límites, que no puede ni integrar ni negar". ${ }^{1}$ Eso que se muestra a sí mismo es "lo místico". Los esfuerzos (vanos) por decir lo que no es expresable a lo que ha dado lugar es, simplemente, a la metafísica tradicional. Esta, en el fondo, no consiste en otra cosa que en la emisión de sinsentidos pero que, pace la lógica, son importantes.

1 J. Bouveresse, Wittgenstain la Rime al la Raison, Les Editions de Minuit, Paris, 1973, p. 22. 
El reino de lo místico en el Tractatus es heterogéneo, es decir, de diferentes clases de "cosas" dice Wittgenstein que es imposible hablar. "En el Tractatus, Wittgenstein argumentó que hay algo que no puede ser puesto en palabras pero que, no obstante, se muestra. Él habla de ello como lo 'trascendental'. Lo trascendental manifiesta tener dos formas de instanciaciones a las que me referiré como la 'lógica' y la 'ético-religiosa' respectivamente". ${ }^{2}$ Nosotros aquí nos concentraremos en la segunda modalidad de los trascendental, pero quisiera decir primero unas cuantas palabras acerca de la modalidad lógica. De hecho ya hemos aludido a ella, puesto que tiene que ver con la forma lógica. Una vez más, la intuición de Wittgenstein, aunque de justificación compleja, es simple. La idea parece ser la de que la forma lógica es una condición necesaria para toda clase de representación: queda introducida eo ipso en el momento mismo en que construimos una figura de algún hecho. Si esto es así, es entonces ilusorio pensar que ella puede a su vez ser representada. Hudson ofrece una metáfora que a mí me parece sumamente ilustrativa: "Todo artista de rango tiene su propio modo de pintar, es decir, de representar el mundo que lo rodea. Sea lo que sea lo que decida pintar, su modo de pintar se manifestará en el producto ya acabado. Sus pinturas no necesitarán firmas: un experto sería capaz de identificarlas como obras de él por el modo como están pintadas. Pero ¿́qué estaríamos pidiendo si le dijéramos a un artista así: No queremos una pintura de nada de lo que ves en el mundo que te rodea. Lo que queremos es simplemente una pintura de tu modo de pintar cosas. Cuidado: no un ejemplo de ese modo! Una pintura del modo mismo!'? Es patente que es ésta una petición que nigún artista podría satisfacer. Ninguna pintura, por abstracta que sea, satisfaría nuestra demanda; ningún auto-retrato, por revelador que fuera, podría satisfacerla. El modo de pintar de un artista se manifiesta en cada una de sus pinturas, pero no puede (lógicamente) ser el tema de ninguno de sus cuadros".3 Lo mismo puede afirmarse, mutatis mutandis, de la forma lógica: es lógicamente imposible referirse a ella y Wittgenstein enfatiza que todo intento por hacerlo no puede más que conducir a absurdos.

Hay que observar que aunque todo esto parece muy razonable, está no obstante expuesto también a objeciones de fuerza de diverso grado. No ahondaré mayormente aquí en este asunto, sino que me limitaré a señalar lo que de hecho es una línea - tal vez decisiva - de crítica. Por otra parte, no estará de más apuntar que fue Russell quien, además de lo dicho por el propio Wittgenstein hacia el final del Tractatus (6.54), primero la.puso en circulación. La idea es sencillamente que Wittgenstein parece incurrir en una clase peculiar de contradicción: de hecho él dice ciertas cosas que, de acuerdo con su pro-

2 W. D. Hudson, Wittgenstein and Religious Belief, The Macmillan Press LTD, Londres, 1975, p. 68.

3 Ibid., pp. 70-71. 
pia teoría, no pueden decirse. Inmediatamente después él añade que se trata de sinsentidos, pero entonces se plantea el problema de cómo un sinsentido puede ser elucidatorio. Regresaré sobre eso más adelante, pero pienso que deberíamos ahora volver la mirada hacia Russell, a fin de ver cómo enfoca él el tema y contrastar posteriormente su tratamiento con el de Wittgenstein.

El trabajo en el que Russell hace explícita su posición acerca de lo que él llama la 'filosofia mística' es su famoso ensayo "Misticismo y lógica"." En ese artículo, Russell establece algunas conexiones importantes entre diversas actividades y fuerzas motrices del hombre y ofrece una caracterización general satisfactoria de su producto. Según él, cuando ciertas tendencias humanas son intelectualizadas lo que surge es la metafísica. Si esto es acertado, entonces el estudio completo del misticismo es, por una parte, un examen "interno" de la Weltanschauung mística (que, obviamente, difiere de la científica o de la concepción del mundo del sentido común) pero, por otra parte, habrá de incluir también un estudio de los impulsos y deseos que a ella conducen. $\mathrm{El}$ estudio de los impulsos constituye precisamente la segunda parte o el segundo aspecto de la teoría de Russell y lo consideraré más abajo, pero primero hay que examinar las características de la filosofía mística.

En el artículo arriba mencionado, la metafísica es definida por Russell como "el intento por concebir el mundo como un todo mediante el pensamiento". 5 Aquí surge una primera diferencia con Wittgenstein. Lo que éste último afirma es que "Sentir el mundo como un todo limitado -es eso lo que es místico". 6 Para él, es lógicamente imposible concebir lo que Russell afirma que se puede concebir (aunque, de nuevo, toda la ontología del Tractatus es una prueba de lo contrario). A su vez, Russell no parece estar muy interesado en los sentimientos que pueda generar o que estén asociados con la comprensión de la totalidad, si bien adopta una actitud de simpatía hacia ellos. Así, pues, Russell acepta a la metafisica en cuanto tal, si bien piensa que los sistemas hasta ahora ofrecidos son falsos, en tanto que Wittgenstein sostiene que el discurso metafísico no es ni verdadero ni falso, sino carente de sentido. De ahí que todo lo que Russell tenga que decir deberá quedar invalidado $a$ priori por la Teoría Pictórica. Ahora bien, si esto fuera todo lo que Wittgenstein quisiera, entonces, asumiendo que sus puntos de vista sobre el lenguaje son correctos, podría decirse que se habría llegado al fin de la controversia: él habría refutado a Russell. El problema es que él por su parte "cede a la tentación de balbucir lo que, en rigor, no puede ser dicho". Es precisamente

4 Bertrand Russell, "Mysticism and Logic", en Mysticism and Logic and Other Essays, Allen and Unwin, Londres, 1976.

5 Ibid., p. 9.

6 L. Wittgenstein, Tractatus Logico-Pbilosophicus, Routledge and Kegan Paul, Londres, 1978, 6.45 (b).

7 L. Villoro, “Lo indecible en el Tractatus”, Crítica, vol. VII, núm. 19, 1975, p. 14. 
este hecho, como ya mencioné, al que Russell apunta en su "Introducción” al Tractatus a través de una observación ingenuamente impertinente: "Lo que nos hace vacilar", dice, "es el hecho de que, después de todo, el sr. Wittgenstein se las arregla para decir un buen número de cosas acerca de lo que no puede decirse". ${ }^{8}$ Aquí hay un problema serio, pues se nos está haciendo ver que no está en lo más mínimo claro (a primera vista por lo menos) por qué ha de aceptarse como significativo y elucidatorio lo que Wittgenstein dice y no lo que otros podrían decir sobre los mismos temas. Si efectivamente son lo temas los que son "intocables", ellos lo serían tanto para unos como para otros. Para intentar salir de la "impasse", a Russell se le ocurre que "hay posiblemente una salida a través de una jerarquía de lenguajes"9 y que el estudio y la comprensión de esa jerarquía tal vez podría ayudarnos a combinar los resultados obtenidos en la filosofia del lenguaje con nuestra tendencia a hablar del modo prohibido. La única posibilidad, en opinión de Russell, para hacer significativo lo que Wittgenstein dice, consistiría en la adopción de alguna versión de la Teoría de los Tipos. Es claro, sin embargo, que esta "solución" no es algo por lo que Wittgenstein pueda optar porque, como sabemos, él rechaza la Teoría de los Tipos, a la que reemplaza por su doctrina de lo que se muestra. "Wittgenstein desarrolló su teoría de lo que se muestra en oposición consciente a lo que se conoce como la teoría de los tipos, que Russell propuso en su filosofia de las matemáticas". ${ }^{10}$ No entraré aquí en detalles, pero puede sostenerse con un alto grado de plausibilidad que Wittgenstein se querella más bien con la letra que con el espíritu de la teoría de Russell. En efecto, él mismo afirma que "La razón por la que una función no puede ser su propio argumento es que el signo para una función ya contiene el prototipo de su argumento y no puede contenerse a sí mismo". 11 Por qué esto último es imposible es algo que Wittgenstein no explica, a pesar de ser el punto crucial. Sin embargo, lo importante para nosotros es notar que de hecho Wittgenstein está aquí defendiendo una cierta jerarquía de tipos lógicos. Lo que él sostiene es que dicha jerarquía se muestra y no es descriptible. Ahora bien, la solución de este problema, en caso de que fuera obtenible, habría de encontrarse en el campo de la lógica filosófica, de la teoría del conocimiento, etc. y ayudaría a resolver los problemas creados por lo trascendental en su modalidad o instanciación lógica. Quedarían, sin embargo, los problemas planteados por lo trascendental en su modalidad ético-religiosa, en relación con la cual la situación podría describirse como sigue: según Wittgenstein, nada de lo que Russell u otros pretenden decir es significativo, si bien es cierto que "Hay en

\footnotetext{
8 B. Russell, "Introduction" en (6), p. xxi.

9 Ibidem.

10 W. D. Hudson, op. cit., p. 75.

11 L. Wittgenstein, op. cit., 3.333 (a).
} 
verdad cosas que no pueden ser puestas en palabras. Ellas se manifiestan. Son lo que es místico"12 Dado que de acuerdo con Wittgenstein, sobre lo místico no hay ni puede haber verdades, él está obligado a circunscribirlo, para no eliminarlo por completo, a la esfera de la voluntad y los sentimientos. Otro modo de describir el contraste entre Wittgenstein y Russell es éste: Russell separa nítidamente el misticismo de la lógica, en tanto que Wittgenstein intenta ver a uno como un resultado de la otra. Como una mera forma retórica (pues tomada literalmente sería poco justa para con Russell) podríamos tal vez decir que la diferencia entre ellos consiste en que Russell quiere decir lo que Wittgenstein comtempla.

Hemos recogido la definición russelliana de 'metafísica' y hemos aludido (nada más que eso) a algunas de sus condiciones de existencia, es decir, ciertos impulsos. Esto, sin embargo, no es suficiente, pues dicha "definición" es demasiada abstracta o general. Pero Russell supera esta insuficiencia al enumerar lo que en su opinión son los cuatro elementos esenciales de toda filosofía mística "en todas las edades y en todas partes del mundo". ${ }^{13}$ Según él, éstas son:

1) La creencia en la superioridad de la intuición frente a la razón

2) La creencia en la unidad del mundo

3) El rechazo de la realidad del tiempo

4) La creencia de que el bien y el mal son mera apariencia.

Una breve caracterización de estos elementos esenciales parece indispensable.

1) El primero de los elementos de toda filosofía mística que Russell menciona tanto constituye una tesis como alude a una experiencia. Es posible que una experiencia así la disfruten más fácilmente, dejando de lado filósofos y religiosos, artístas y matemáticos. La idea es que en un momento de particular concentración, después de un largo perídodo de trabajo, se llega a "ver" un cierto resultado, uno "comprende" que la cosa tiene que tener tal o cual propiedad, ser de esta o aquella clase, y este resultado, demostrable o no, no podría nunca haber sido alcanzado por los laboriosos métodos de trabajo y razonamientos usuales (pruebas, ejercicios, experimentos, etc.). Russell habla de esta clase de experiencia ( $\mathrm{y}$ no dudo de que al hacerlo nos esté proporcionando un valioso dato autobiográfico) en su libro Nuestro conocimiento del mundo externo. De modo sorprendente, puesto que él está allí exaltando la "filosofía científica" y alabando su método, es decir, el análisis, él afirma que "Cuando se ha hecho todo lo que puede hacerse mediante el método, se alcanza una etapa en la que únicamente la visión filosófica directa puede llevar-

12 Ibid., 6.522.

13 B. Russell, Mysticism and Logic, p. 14.' 
nos más adelante. Aquí sólo contará el genio. Lo que se quiere, por lo general, es un nuevo esfuerzo de imaginación lógica, que se vislumbre una posibilidad nunca antes considerada y la percepción directa de que esta posibilidad está realizada en el caso en cuestión". ${ }^{14}$ Los momentos cruciales en las investigaciones, por lo tanto, se producirían gracias a un mecanismo mental que no es "metodizable". Sin intuición no habría progreso intelectual. Por otra parte, una diferencia importante entre la "intuición" del lógico o del científico y la del religioso procedería de la diferencia entre los "objetos" contemplados en cada caso. Pero las experiencias mismas parecería ser de la misma "calidad". En el caso del filósofo, lo que sucede es que él transita a un estado mental particular, un estado generado por "una cierta sabiduría, súbita, penetrante, coercitiva, a la que se le contrasta con el estudio lento y falible de la apariencia externa y que descansa por completo en los sentidos". ${ }^{15}$ Russell habla de un "sentimiento extraño" que elimina todas las dudas. Y este sentimiento, tarde o temprano, lleva a la depreciación del mundo del sentido en favor de otra realidad, que es el fundamento de la primera y en relación con la cual podemos hablar de genuino conocimiento. La comprensión última del mundo se lograría, pues, por "intuición".

2) Si en el primer caso el adversario del metafísico lo eran, en primer lugar, los sentidos y los métodos empíricos de conocimiento, en este segundo caso el enemigo declarado es el análisis. La intuición metafísica en este caso consiste en ver la realidad como un todo indivisible y en rehusarse a considerarla como un agregado de cosas o hechos discretos, últimos, independientes. La idea es que el análisis es en última instancia "falsificación”, "abstracción", "mutilación". Tampoco es el conocimiento ninguna suma de ideas, como quieren los empiristas. De este modo, todo el programa empirista en teoría del conocimiento, en metafísica y en la filosofía del lenguaje (como, por ejemplo, cuando se sostiene que el estudio filosófico del lenguaje debe empezar con los "átomos de significado") es rechazado y se mantiene que sólo gracias a una intuición peculiar puede verse el mundo como realmente es, o sea, como un todo orgánico en el que sus partes están interrelacionadas y que son lo que son debido a eso, i. e., porque sus relaciones son parte de su naturaleza. Toda división es artificial y es producida por un enfoque fragmentario y limitado de la realidad.

3) La idea de que el tiempo es irreal es particularmente importante y representa una posible salida para un considerable número de problemas metafísicos y morales. Lo que en este caso se afirma es, en primer lugar, que lo que es genuinamente real no está en el tiempo y, por lo tanto, es inmune al

14 B. Russell, Our Knowledge of the External World, Allen and Unwin, Londres, 1980, p. 245.

15 B. Russell, Mysticiss and Logic, p. 14. 
cambio. Esto, como veremos, es una idea muy importante tanto para Russell como para Wittgenstein. Este último piensa que es posible ver el mundo sub specie aterni y Russell considerará esa posibilidad como un ideal importante para la acción política y personal. Como intentaré dejar en claro, están aquí involucrados dos usos diferentes de la misma idea.

4) El cuarto elemento de la "filosofía mística", es decir, la idea de que el bien y el mal son únicamente aparentes, está íntimamente ligada a la idea de que la realidad es Una. En ambos casos se sostiene que los puntos de vista contrarios ignoran el hecho de que la mente humana no puede ser omniabarcadora. En este punto, Russell y Wittgenstein chocan violentamente.

Russell rechaza las tesis del místico. Sin embargo, su posición también es paradójica, pues él mantiene que la actitud del místico, una actitud asociada con las tesis que ha previamente rechazado, es sumamente valiosa. En otras palabras, lo que en este contexto podríamos llamar la 'paradoja de Russell' consiste en que por una parte él repudia intelectualmente al misticismo, pero por la otra propone su adopción debido a la "sabiduría" que transfiere en cuanto al modo de sentir. Para comprender cómo es posible defender una posición así será forzozo presentar, si bien lo haré de modo esquemático, ciertos aspectos de su concepción de la naturaleza humana. Pero antes intentaré detectar cómo recoje el Tractatus los elementos de los que Russell habla.

Yo estoy convencido de que, aunque tal vez resulte equívoco introducir la palabra 'intuición' del modo vago en el que se le usa en el discurso normal para referirnos a algún rasgo del sistema de Wittgenstein, la doctrina de lo que se muestra le concede un lugar en él. Hay ciertas cosas que, aunque indecibles, son aprehendidas. ¿Cómo se les aprehende? Wittgenstein habla de "ver" y de "sentir". Podemos "ver" correctamente el mundo (6.54) y sentirlo como un todo limitado (6.45 a). Ahora bien, a pesar de las múltiples diferencias que hay entre los diversos conceptos involucrados, "ver" y "sentir" parecen cubrir la misma función que usualmente se le asigna a la intuición. La coincidencia de nociones, de todos modos, no es total. Una restricción al uso de 'intuición' en el contexto del Tractatus es, por ejemplo, que el sentimiento que Wittgenstein tiene en mente sólo puede gestarse sobre la base de un conocimiento profundo y extenso de la lógica, pero, por otra parte, diferencias como ésta no parecen bastar para impedirnos aseverar que Wittgenstein efectivamente introduce en su sistema el elemento que Russell menciona. La intuición es no sólo de lo inefable, de lo que se muestra a sí mismo, sino que eso que se muestra a sí mismo es en el fondo lo que realmente importa. Este punto de vista está abiertamente reconocido por Wittgenstein en una carta a Fricker. "El interés del libro es ético. En algún momento tuve la intención de incluir en el prefacio una oración que de hecho ahora no está allí, pero que ahora escribiré aquí para tí, porque tal vez sea'para tí una clave para el libro. Lo que yo 
tenía la intención de escribir, entonces, era esto: Mi obra consta de dos partes: La presentada aquí más todo lo que no he escrito. $Y$ es precisamente esa parte la importante". ${ }^{16}$ En este sentido, el sentimiento del que Wittgenstein habla es superior a cualquier otro método o enfoque o modo de aprehender la realidad. Sabemos que todas las pseudoproposiciones de la metafísica tradicional, que se pretendía que expresaran ese sentimiento, son sinsentidos lógicos, pero Wittgenstein no comete el grave error de pensar, como lo hicieron los positivistas, que con esto llegamos al fin del asunto. Al contrario. Como ya dije, es precisamente a partir de este momento que nos enfrentamos a las cuestiones que realmente importan, las cuales, sin embargo, no permiten que se diga nada acerca de ellas. La intuición o el sentimiento, por lo tanto, tienen un papel vital que desempeñar.

La idea de que la realidad es una está dada por la ontología del Tractatus. Hay únicamente hechos y éstos se componen de objetos que son la sustancia de todos los mundos posibles. Lo que cambia son las configuraciones de los objetos, como resultado de una urgencia interna (al igual que las mónadas de Leibniz), puesto que Wittgenstein rechaza la causación como una relación objetiva. Los hechos pueden ser de diversa clase (mentales, físicos, etc.). y, en último análisis, son lógicamente independientes unos de otros, pero sus elementos son siempre los mismos. Aquí aparece, pues, una primera idea de unidad. El carácter unitario de la realidad se refuerza cuando pasamos, por así decirlo, al nivel ontológico más profundo, es decir, aparece con el conocimiento a priori (y no empírico) del material de los hechos. Pero la idea de unidad también tiene en el Tractatus otra instanciación, pues parece asimismo en un nivel ontológico "superior", esto es, cuando consideramos la idea de totalidad de los hechos al sentírseles formando un todo limitado. El rechazo wittgensteiniano de la división y la pluralidad no es similar al de los monistas: el atomismo lógico de Wittgenstein es radical y de acuerdo con él el mundo se divide en hechos que son enteramente independientes unos de otros en el espacio y en el tiempo. "Nos bastará constatar que el universo del Tractatus", nos dice Bouveresse, "es, de todos modos, un universo completamente atomizado, no sólo en el espacio sino también en el tiempo, en el cual no hay lugar para la continuidad y el movimiento, un universo sin acontecimientos y sin historia". ${ }^{17}$ Sería, por lo tanto, un terrible error pensar que porque puede rastrearse la idea de unidad de la realidad (de la totalidad de los hechos) en el Tractatus, Wittgenstein se ve comprometido con algo como el axioma de las relaciones internas. Él está lejos de concebir la realidad como un "todo orgánico". Su admisión de la unidad procede de la tesis de la homogeneidad

16 Citado en P. Englemann, Letters from Ludwig Wittgentein (with a Memoir), Basil Blackwell, Oxford, 1967, p. 143.

17 J. Bouveresse, op. cit., p. 47. 
del material del mundo y de la noción cuantitativa de totalidad. No se sigue, sin embargo, que la idea de unidad esté ausente, sino tan sólo que difiere de otras, más tradicionales.

Los dos últimos elementos de la filosofía mística enumerados por Russell son igualmente esenciales al misticismo de Wittgenstein. Consideremos primero la idea de que el tiempo es irreal. En el Tractatus hay dos proposiciones relevantes en conexión con esto: la proposición 6.4211 (b) y la proposición 6.45 (a). Esta última enuncia que "ver el mundo sub specie aeterni es verlo como un todo - un todo limitado". Por otra parte, la primera nos dice que "Si por eternidad queremos decir no duración temporal infinita, sino atemporalidad, entonces vive eternamente quien vive en el presente". No es muy fácil establecer una conexión entre estas dos proposiciones, pero parecería que lo que se quiere decir es que vivir en el presente es vivir sin inquietud por lo que fue, es o será el caso. Vivir en el presente, por lo tanto, sólo puede ser vivir en la contemplación de lo que es atemporal, es decir, los objetos, y ante el "hecho" de que hay un mundo. La contemplación de los objetos es la contemplación de lo que es necesario o, dicho de otro modo, de lo que no puede más que ser. La vida en el presente, en el sentido del Traciatus, conduce a o es la manifestación directa de la experiencia mística del mundo como un todo limitado.

Ahora bien, quien vive en el presente y logra contemplar el mundo como un todo limitado se dará cuenta de que el mundo no contiene valores. "En el mundo todo es como es y sucede como sucede: en él no hay valores -y si los hubiera, no tendrían ningún valor". ${ }^{18}$ En teoría, el mundo podría ser completamente descrito, pero a la descripción no pertenecería ningún juicio de valor. Todos los hechos tienen exactamente el mismo valor, es decir, no poseen ningún valor. Los hechos son éticamente neutros. Expresado lingüísticamente, esto equivale a decir que "Todas las proposiciones son de igual valor"19 y que "Las proposiciones no pueden expresar lo más alto". ${ }^{20}$ La ética, por lo tanto, es inexpresable o, como dice Wittgenstein, 'trascendental'. Aquello sobre lo que supuestamente versan las proposiciones éticas, esto es, el bien, el deber ser, etc., no es parte del mundo. Pero es obvio que no tiene sentido decir ni insinuar que puede haber algo fuera del mundo. De ahí que los “objetos" de la ética sirvan más bien para fijar los límites del mundo y se les "alcance” a través de la acción (buena o mala) y a través de la creación artística, porque "Ética y estética son lo mismo". ${ }^{21}$

18 L. Wittgenstein, Tractatus, 6.41 (b).

19 Ibid., 6.4.

20 Ibid., 6.42 (b).

21 Ibid., 6.421 (c). 
Es, pues, claro que el sistema de Wittgenstein incluye lo elementos que Russell considera que son esenciales a la filosofía mística. En el sentido de Russell, por lo tanto, la filosofía de Wittgenstein es también una filosofía mística. Ahora bien, deseo sostener que esos elementos también los encontramos en la obra del propio Russell, si bien aparecen - por así decirlo- “disfrazados', esto es, emergen de modo distinto a como cobran forma en la obra de Wittgenstein. Para hacer ver eso, habremos de esbozar su teoría de la naturaleza humana.

La antropología filosófica de Russell está expuesta en su extraordinario libro Principles of Social Reconstruction. El libro es el resultado de la compilación de las conferencias que Russell impartiera en 1916 como parte de su actividad pacifista y que terminarían llevándolo a la cárcel. Ya podemos aquí señalar una diferencia entre los misticismos de Russell y Wittgenstein: el de Wittgenstein es el del solitario, el del hombre que se asombra ante la existencia del mundo y para quien las acciones humanas no son a final de cuentas más que un conjunto insignificante de los hechos del mundo, sin nada especial que los distinga del resto. El misticismo de Russell, por su parte, está relacionado con el Hombre, o mejor dicho, con los hombres, y depende de esta conexión, es decir, surge de consideraciones acerca de sus acciones, de su historia, su futuro, esperanzas, etc. El misticismo de Wittgenstein es lógico, el de Russell social. Y, obviamente, los modos de vida que sugieren y promueven serán radicalmente diferentes.

Aunque siempre en sus escritos morales y políticos Russell toma abiertamente partido por los puntos de vista que defiende, en Principles of Social Reconstruction encontramos algo más, a saber, un tono especial: el tono del visionario, del iluminado. Esto es así porque, como intentaré mostrar, él se ve a sí mismo como elaborando una clase de filosofía diferente de la filosofía "técnica" cuyo método correcto es el análisis y su objetivo el descubrimiento de las verdades más generales o abstractas acerca del mundo y en la que se integran de modo esencial descripciones y evaluaciones. La distinción no es del todo clara pero puede, creo, sostenerse. Lo que es importante enfatizar es que la "filosofía mística" de Wittgenstein emerge como un resultado de filosofía stricto sensu, en tanto que la "filosofía mística" de Russell es producida de modo deliberado como filosofia lato sensu. Una vez dicho esto, consideremos ahora algunas de las ideas del texto principal de Russell a este respecto.

Para nuestros propósitos, podemos considerar como la idea central de la antropología filosófica de Russell la idea de que el Hombre está motivado fundamentalmente por impulsos, en tanto que los deseos conscientes tan sólo reflejan el conflicto de fuerzas que tiene lugar en una "región" más profunda de la estructura de la personalidad humana. Sobre esto, Russell no hace más que repetir, en un lenguaje diferente, lo que Hume ya había dicho y expresado 
a través de su maravillosa fórmula "La razón es y debe ser la esclava de las pasiones". Hay, no obstante, una diferencia esencial entre ellos: la concepción de Hume es propuesta como si se tratara de una super-teoría, de una concepción ultra-científica de clase especial, en tanto que Russell explícitamente ofrece una cierta interpretación del ser humano. Gracias a ella se podrán proponer ideales con base en los cuales se podrá juzgar acciones y modificar instituciones. Pero debe quedar claro que en ningún momento pretende Russell estar ofreciendo "pruebas" o "demostraciones" en favor de su concepción. Los criterios de elección aquí no son los de la filosofia en sentido estricto o técnico.

Las acciones del hombre, de acuerdo con el modelo o cuadro que Russell nos pinta, emanan de tres fuentes diferentes: el instinto, la mente y el espíritu. En cada una de estas "esferas" de vida encontramos dos clases de impulsos y deseos: impulsos y deseos de creación e impulsos y deseos de posesión; o, en otras palabras, impulsos y deseos que propician o favorecen la vida e impulsos y deseos que promueven la muerte. La vida del instinto está constituida por todo lo que compartimos con los animales: la nutrición, la reproducción, el amor al grupo, a la tierra, etc. La vida de la mente es "la vida de la búsqueda del conocimiento". ${ }^{22}$ La curiosidad innata, el amor a la sabiduría y a la verdad, etc. son casos de impulsos intelectuales o mentales. Ahora bien, una buena vida es una vida completa. Es por eso que inclusive si al desarrollo instintivo se añadiera el éxito mental, ello no bastaría para poder hablar de una "vida buena". Para tener una vida completa es necesario, además, ser capaz de universalizar las metas que se tenga y esto sólo puede lograrse mediante la vida del espíritu, es decir, a través de la vida de los "sentimientos impersonales".

Así como la vida instintiva exitosa da lugar a un sentimiento de poder y de fuerza individual, a una alegría intensa e incomparable, la auténtica vida esperitual o religiosa conduce al hombre a una integración sentimental con todo lo que tiene vida y a un sentimiento de alegría respetuosa ante el "hecho" de que hay mundo. "Es posible sentir el mismo interés por las alegrías y tristezas de otros como por las propias, amar y odiar independientemente de toda relación con nosotros, preocuparse por el destino del hombre y el desarrollo del universo sin un pensamiento de que estamos personalmente involucrados. Reverencia y adoración, el sentimiento de mandato incondicional y de actuar bajo órdenes que la religión tradicional ha interpretado como inspiración divina, todo ello pertenece a la vida del espíritu. Y más profundo que todo esto está el sentido de un misterio a medias revelado, de una sabiduría y una gloria ocultas, de una visión transfiguradora en la que las cosas comunes pierden su importancia sólida y se vuelven un tenue velo detrás del cual se deja entrever le verdad última acerca del mundo. Son sentimientos como estos la fuente de

22 B. Russell, Principles of Social Reconstruction, Allen and Unwin, Londres, 1971, p. 143. 
la religión y si tuvieran que extinguirse la mayor parte de lo mejor de la vida se desvanecería". 23

Por poco que pueda parecer, pienso que ya disponemos de la información necesaria para detectar los cuatro elementos que Russell considera esenciales para toda filosofia mística. Dichos elementos efectivamente están allí, sólo que implícitamente. Nuestra tarea consistirá en sacarlos a luz.

Consideremos primero la idea de la unidad de la realidad. Esta está expresada, en primer lugar, en conexión con el sentimiento de pertenencia al todo, o más bien, con el sentimiento de que es posible que la vida del individuo se funda con todo lo que tiene vida en el universo. Este sentimiento rompe las barreras de lo privado y lo subjetivo y es entonces que puede verse o sentirse el mundo como una sola cosa. Esto nos permite comprender también cómo podía Russell sostener la idea de que el tiempo es irreal: si podemos sentirnos inmersos en la corriente de la vida, entonces la muerte del individuo no equivale a su completa aniquilación, puesto que el universo, al cual pertenece y con el cual se identifica, persiste. De este modo, el individuo puede tener la sensación de que vive eternamente y de que las clasificaciones temporales proceden de un contacto fragmentario con la totalidad de las cosas. Russell da expresión a esto, en combinación con algunas otras ideas, como sigue: "El mundo tiene necesidad de una filosofía que promueva la vida. Pero para promover la vida es necesario evaluar algo distinto de la mera vida. La vida consagrada únicamente a la vida es animal, sin ningún valor real, incapaz de preservar a los hombres de modo permanente del tedio y del sentimiento de que todo es vanidad. Para que la vida sea plenamente humana ésta debe estar al servicio de algún fin que, en algún sentido, parezca estar fuera de la vida humana, algún fin impersonal y por encima de la humanidad, como Dios o la verdad o la belleza. Quienes mejor promueven la vida no tienen a la vida como su objetivo. Ellos aspiran más bien a lo que parece una encarnación gradual, un traer a nuestra existencia humana algo eterno, algo que aparezca a la imaginación como viviendo en un cielo alejado de la lucha, del fracaso y de las devoradoras fauces del Tiempo". ${ }^{24} \mathrm{El}$ tiempo es algo real y algo que vale para cada uno de los seres, cosas, objetos, etc. considerados aislada o distributivamente, pero no cuando se les considera colectivamente, Ahora bien, este ver al mundo como un todo no es ni un ver intelectual ni un resultado del análisis, de la investigación, etc. Russell enuncia claramente su posición a este respecto: "La filosofía que deseo defender puede llamarse atomismo lógico o pluralismo absoluto porque, aunque mantiene que hay muchas cosas, niega que haya un todo compuesto de esas cosas". ${ }^{25}$ Se trata más bien

23 Ibid., pp. 143-44.

24 Ibid., Pp. 168-69.

25 B. Russell, "On Scientific Method in Philosophy", en (4), p. 84. 
de un modo de sentir. Esto a su vez permite ver cómo, simultáneamente al primer elemento mencionado por Russell, aparece el segundo, i.e., la idea de que hay una "vía" hacia la comprensión que no es la de la ciencia. Porque el filósofo místico "comprende" algo, algo adquirido gracias a las "intuiciones" del espíritu, algo inefable y expresable, si lo es, sólo a través del arte (“El arte arranca del instinto y se eleva hasta la región del espíritu") ${ }^{26}$ y a través de la acción. Pero, una vez más, lo que es importante es que la contemplación del mundo originada en la experiencia religiosa es imposible de alcanzar mediante las actividades de la mente. Así, Russell admite la idea de que es de algún modo posible "conocer" el mundo en un sentido diferente (obviamente, no en un sentido proposicional) que mediante la observación, la experimentación, el análisis, etc.

Lo que tal vez merezca un exámen más detallado sea el cuarto elemento, es decir, la idea de que el bien y el mal son sólo apariencia. Vimos ya que para Wittgenstein no son ni apariencia ni no-apariencia: simplemente no son parte del mundo. No hay hechos de valor. Russell estaría de acuerdo con eso, pero él sostendría que los valores entran en escena con el Hombre. El bien que nos importa es "el bien que está a nuestro alcance crear —el bien en nuestras propias vidas y en nuestras actitudes hacia el mundo". ${ }^{27}$ Pero el bien y el mal son irreales en el sentido de que podemos ser indiferentes hacia ellos. "En la religión, y en toda concepción profundamente seria del mundo y del destino humano, hay un elemento de sumisión, un darse cuenta de los límites del poder humano, que es algo que falta en el mundo moderno, con su rápido éxito material y su insolente creencia en las ilimitadas posibilidades de progreso $(. .$.$) . La sumisión que la religión inculca en la acción es esencialmente$ la misma en espíritu a la que la ciencia enseña en el pensamiento". ${ }^{28} \mathrm{Y}$, como ya ha sido señalado, por ejemplo por Brightman en su artículo "Russell's Philosophy of Religion" — “De su sentido místico de infinitud y de membrecía al todo fluye el tercer rasgo de su religión, a saber, la resignación. (...). La resignación religiosa no es aprobación de todo lo que existe; consiste más bien en 'no estar sometido al enojo ni a la indignación ni al preocupado pesar'. La resignación es la actitud de un participante, no de alguien que está fuera". ${ }^{29}$ Es en este sentido (i.e., la posibilidad de ser indiferente ante ellos) que el bien y el mal pueden ser irreales.

Resumiendo: la vida completa es la vida buena, pero su bondad varía dependiendo de nuestros deseos y nuestros objetivos ( $y$, a fortiori, de nuestras

26 B. Russell, Principles of Social Reconstruction, p. 29.

27 B. Russell, Mysticism and Logic, p. 29.

28 Ibid., p. 29.

29 E. S. Brightman, "Russell's Philosophy of Religion", en The Philosophy of Bertrand Russell, editado por P. A. Schilpp. Northwestern University, Evanston and Chicago, 1944, p. 553. 
actividades). Aquí es necesario observar un ligero conflicto en el esquema de Russell, porque la vida religiosa o espiritual parece ser continua con la del instinto y, cuando se tiene de ella una experiencia plena, sencillamente la cancela, sublimándola. No es por mera coincidencia que Russell dice lo que dice en su famosa Introducción a su Autobiografía. ${ }^{30}$ Amor, conocimiento y piedad son los resultados naturales de una vida activa completa, los valores centrales o paradigmáticos en cada una de las esferas mencionadas, i. e., instinto, mente y espíritu. Pero el "amor" puede transformarse, puede perder sus objetos particulares sobre los cuales se ejerce y hacerse más y más universal. Hablamos entonces, entre otras cosas, de justicia social.

Tal vez no estará de más recordar que lo que hasta aquí hemos hecho ha sido presentar aspectos de la filosofía del Tractatus y elementos de los escritos de Russell que Russell caracteriza como los propios de la filosofía mística. Como ya vimos, lo que Russell nos da es una lista de ideas y estados anímicos que parecen ser condición necesaria para hablar de filosofía mística en absoluto. Pero no es claro que sean también condición suficiente. B. F. McGuinness, por ejemplo, sostiene que los cuatro elementos mencionados por Russell están efectivamente presentes en el Tractatus, pero que en éste hay, además, un quinto factor. "En verdad, el misticismo de Wittgenstein no sólo abarca los cuatro elementos de Russell que ya ha considerado - la impotencia de la voluntad, la naturaleza de la ética, la inmortalidad que confiere la atemporalidad y el desvanecimiento del problema de la vida - sino también una forma peculiar de solipsismo que en el Tractatus está bosquejada en 5.62-5,63". 31 Ahora bien, si nuestra reconstrucción ha sido fiel y lo que McGuinness dice es acertado, entonces lo que él está haciendo es mencionar no uno sino por lo menos tres nuevos elementos del misticismo, puesto que por lo menos dos de los elementos que él enumera (el primero y el cuarto) simplemente no están incluidos en la lista de Russell. De hecho, éste ni siquiera los menciona. Por otra parte, debería también ofrecerse por lo menos algún argumento en favor de la tesis de que la filosofía de Russell ni siquiera implícitamente contiene los elementos del misticismo de Wittgenstein. Esto, naturalmente, McGuinness no lo hace. Nosotros, por lo tanto, deberemos examinar aquí los nuevos elementos del misticismo que McGuinness destaca y tratar de determinar si no están, de uno u otro modo, presentes en el pensamiento de Russell.

Aparentemente, pues, son tres los temas con los que Wittgenstein enriquece lo que Russell llamaría la 'filosofía mística', a saber, la impotencia de la voluntad, el desvanecimiento del problema de la vida y el solipsismo. Ahora bien, nótese que Russell de hecho no da una explicación de por qué considera

30 B. Russell, "Prologue. What I Have Lived For”, en The Autobiography of Bertrand Ruovell, Allen and Unwin, Londres, 1967, vol. I, p. 13.

31 B. F. McGuinness, "The Mysticism of the Tractatus”, Philosophical Review 75, 1966, p. 307. 
que los temas que él señala son esenciales a la filosofía mística. El simplemente los enumera. Cabe entonces preguntar: isucede lo mismo con Wittgenstein o dispone éste de algún criterio para añadir (o eventualmente quitar) algo en esa lista? La respuesta es prístina: desde la perspectiva de Wittgenstein, lo místico quedará determinado como todo aquello que de acuerdo con la teoría del lenguaje del Tractatus resulte inexpresable. Hay, pues, un criterio wittgensteiniano para "lo místico": lo indecible. En este punto, por lo tanto, la posición de Wittgenstein es más clara que la de Russell.

Esto que acabamos de decir es importante porque no tomarlo en cuenta es correr el riesgo de no comprender lo que McGuinness afirma. Por ejemplo, a primera vista por lo menos, no se entiende qué tiene que ver el solipsismo con lo místico. Muchos filósofos - y Russell entre ellos- dirían que la cuestión del solipsismo es un asunto de filosofía de la mente y de teoría del conocimiento, pero que en la medida en que pueden ofrecerse argumentos y ofrecer lo que prima facie serían demostraciones (en el sentido que sea) por lo menos en principio no habría aquí involucrado ningún misterio (por más que la problemática resulte, como de hecho lo es, tremendamente difícil). Y lo mismo podría sostenerse del Tractatus. Después de todo, si hay algo técnico en el libro son las consideraciones sobre los contextos oblicuos y la crítica a la "teoría moderna del conocimiento", discusiones que terminan con un rotundo rechazo del "yo". Podría entonces pensarse que un rechazo del sujeto metafisico de hecho equivale a una refutación del solipsismo. Desafortunadamente, el asunto es un poco más complejo. Independientemente de que el "yo" sea o no una entidad real, de todos modos, como McGuinness acertadamente señala, seguiría habiendo en relación con aquello de lo que hablamos cuando hablamos del "yo" (sea éste una construcción, un supuesto, etc.) cosas que no se pueden decir.

Porque lo que el solipsista quiere decir es perfectamente correcto, sólo que no puede decirse, sino que se muestra.

El mundo es mi mundo: esto se manifiesta en el hecho de que los límites del lenguaje (del único lenguaje que yo comprendo) significan los límites de $m i$ mundo. $^{32}$

Ahora bien ¿qué es eso que en conexión con el solipsismo no se puede decir y que, sin embargo, se muestra? Aquí no podremos extendernos mayormente sobre el tema, pero ofrezco la siguiente respuesta: lo que se manifiesta permanentemente en el uso del lenguaje (en este caso del pronombre 'yo' y nociones asociadas) es el lugar privilegiado del hablante (i. e., de cada hablante) como centro del lenguaje que de todos modos es público. No hay ningún lenguaje que pudiera expresar ese "hecho" (y si lo hubiera no sería 
un lenguaje que comprenderíamos), pero ello se muestra cada vez que hablo, escucho, reflexiono, etc. En palabras de Wittgenstein, "Yo soy mi mundo (El microcosmos)" ${ }^{33}$ Esto está también conectado con otro pensamiento importante, el cual sin embargo me parece ligeramente menos aceptable que otros: "Mundo y vida son lo mismo". ${ }^{34}$ De esto se sigue que mi mundo (el mundo) es mi vida y eso es solipsismo, haya o no un "yo" poseedor. Es claro, también, que decirlo es emitir un sinsentido.

En relación con el solipsismo, Russell no tiene nada que decir que lo ligue ni con los temas tradicionales de la filosofía mística (como él la concibe) ni con el misticismo wittgensteiniano. Para él, la cuestión de la existencia del yo y la verdad del solipsismo parecen ser si no la misma cuestión por lo menos sí estar estrechamente ligadas: si el yo no existe, el solipsismo es automáticamente falso. Pero la cuestión de la existencia del yo-sustancia es, en principio, algo que tiene una solución definitiva, por más que hasta hora no se le haya encontrado. Es precisamente aquí, empero, que Wittgenstein se revela como un pensador más profundo que Russell. Lo que el autor del Tractatus nos está diciendo es que aunque Russell lograra demostrar la existencia o la no-existencia del yo, de todos modos seguiría siendo un problema el que el mundo tuviera que ser contemplado, conocido y descrito desde una perspectiva particular (la mía) y es eso lo que no podría ser expresado en el lenguaje, sino que sólo se mostraría. Sucede lo mismo, mutatis mutandis, con quien postula una existencia futura para explicar esta. “ $\vdots O$ se despeja algún misterio por mi eterna existencia? ¿No es esta vida eterna tan misteriosa como la presente?”. ${ }^{35} \mathrm{Se}$ ve, pues, que Russell antepone una problemática a otra y deja sin resolver esta última. De ahí que pueda sostenerse que es Wittgenstein quien va realmente a los fundamentos del asunto y cuya posición parece ser la correcta.

Un segundo tema del misticismo wittgensteiniano es el del desvanecimiento del problema de la vida. Una vez más, desde la perspectiva de Wittgenstein aquí hay un elemento de misticismo, puesto que hay algo que puede comprenderse pero que, cuando efectivamente es comprendido, nos hace ver que es indecible. "La solución del problema de la vida consiste en el desvanecimiento del problema.('No es esa la razón por la que aquellos a quienes después de un largo período de duda se les aclaró el sentido de la vida no pudieron entonces decir en qué consistía ese sentido)" ${ }^{36}$ El problema del sentido de la vida se plantea porque se mal emplea el lenguaje. Cuando se comprende la lógica de nuestro lenguaje se comprende que hay cierta clase de preguntas (e.g., preguntas acerca de totalidades infinitas, de rasgos no factuales de la realidad,

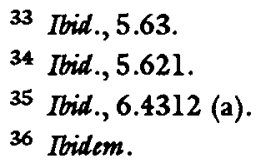


etc.) para las cuales no hay respuesta, pero no porque sea muy dificil hallar o construir dichas respuestas, sino porque las preguntas subyacentes, que fueron aceptadas como legítimas, rebasan los límites de la significatividad. Dicha preguntas son significativas sólo aparentemente. "Cuando la respuesta no puede ser expresada, tampoco puede serlo la pregunta. (...) El misterio no existe. (...) Si se puede formular una pregunta, también debe ser posible responderla". ${ }^{37} \mathrm{Y}$ es claro que no es posible decir en qué consiste el sentido de la vida. Tal vez pueda uno sentir que uno puede contemplar su vida como un todo y hablar de ella, pero es claro que "decirlo" es decir un sinsentido, porque para que ello fuera posible tendría uno que poder situarse fuera de su propia vida y contemplarla, por así decirlo, a distancia. Esto es imposible (y decirlo, absurdo), pero ello no obsta para que el sentimiento en cuestión sea un sentimiento místico genuino, puesto que resulta de la aprehensión de algo y de la imposibilidad de expresarlo.

En relación con esta cuestión, yo pienso que lo que Russell tendría que decir sería a final de cuentas bastante convencional. Para él, el sentido de la vida y de las acciones humanas tendría que estar fijado por ciertos ideales o entidades especiales (e.g., Dios). El problema es que Dios, la belleza, la Verdad, el Amor, etc. son el resultado de proyecciones sublimizadas o idealizadas a partir de lo empíricamente dado. Para Wittgenstein, nada de eso puede tener valor. "El sentido del mundo debe ubicarse fuera del mundo". 38 Aún suponiendo, per impossibile, que el Ser Supremo constituyera el sentido del mundo, ello no podría expresarse en el lenguaje (regido por la inexorable sintaxis lógica y teniendo como objetivo la producción de "figuras" de la realidad), puesto que "Dios no se manifiesta en el mundo". ${ }^{39}$ Por consiguiente, desde la perspectiva wittgensteiniana las respuestas russellianas posibles resultarían insatisfactorias. Una vez más, la posición de Wittgenstein parece ser, en profundidad y solidez, superior.

McGuinness menciona un elemento más - viz., la impotencia de la voluntad - como un tema que aparecería tanto en la lista russelliana de temas místicos como en la wittgensteiniana. Por lo pronto, podemos constatar que en lo que a Russell atańe esto es un error total. Es claro que nada de lo que Russell afirma sugiere siquiera una conexión distante con lo que McGuinness dice y es un tanto sorprendente el que se le atribuya a Russell una idea así. Este más bien diría lo contrario: nosotros podemos (y debemos) influir en el mundo. Para permitir eso, es decir, orientar nuestras acciones en uno u otro sentido, sirve la filosofía en sentido amplio! El tema mencionado por McGuinness no es, pues, un tema de la filosofía mística russelliana. Podría, sin

\footnotetext{
37 Ibid., 6.5.

38 Ibid., 6.41.

39 Ibid., 6.432.
} 
embargo, tratarse de un tema específicamente wittgensteiniano. No obstante, también es difícil estar de acuerdo con esto. En mi opinión, 'impotencia de la voluntad' tiene dos posibles lecturas en el Tractatus:

a) imposibilidad de alterar hechos en el mundo (rechazo de la causalidad)

b) imposibilidad de introducir valores en el mundo

Independientemente de cuál sea la lectura por la que optemos (podríamos inclusive aceptar las dos), no se ve en ninguno de los casos que haya una conexión interesante entre ellas y la doctrina de lo inexpresable. El tema cimpotencia de la voluntad", por lo tanto, no tiene nada que ver ni con lo místico wittgensteiniano ni con lo religioso russelliano.

Estamos ahora en posición de delinear con mayor precisión los contornos de los pensamientos de Russell y Wittgenstein en torno a los "temas importantes", de poner de relieve semejanzas y diferencias fundamentales entre sus enfoques y posiciones y, tal vez, de emitir alguna evaluación. Para el primero, lo determinante son los temas y las tesis o intuiciones que les subyacen, pero hay que señalar que nunca nos dice por qué esos temas y esas tesis y no otros son los característicos de la filosofía mística. Para el segundo, lo místico queda caracterizado fundamentalmente a través de su doctrina de lo indecible. Esto explica por qué, mas que de misticismo, Russell habla de "filosofía mística", en tanto que Wittgenstein alude más bien a "lo místico". Podemos de todos modos inferir que algo de correcto debe haber en la concepción de Russell, puesto que de hecho los temas russellianos se encuentran, como he tratado de hacer ver, considerados ( $\mathrm{y}$ tal vez podría decirse 'elucidados') en el Tractatus. Y hay también que reconocer que la inversa no vale: sobre lo que para Wittgenstein no se puede hablar (el sentido de la vida y la posición privilegiada del sujeto o del hablante) Russell no tiene nada que decir. El pensamiento de Wittgenstein es, pues, más amplio que el de Russell. Si es también más profundo es una cuestión debatible.

A mí me parece que el examen de las concepciones de lo místico y lo religioso, tal como hemos venido usando los términos, no deberían limitarse al mero análisis conceptual. Creo que sería interesante tratar de sacar a la luz algunas de las implicaciones de dichas concepciones y creo que un buen ejemplo lo constituye la noción de felicidad. Veamos qué es lo que al respecto nos dicen los pensadores de los que aquí nos ocupamos.

Parecería que tanto Russell como Wittgenstein estarían dispuestos a aceptar la ecuación 'Vida buena = Vida feliz', sólo que ese acuerdo sería puramente formal. Para Wittgenstein, la felicidad consiste en la aceptación del mundo tal como es, en no sentirse afectado por nada de lo que de hecho acontece. La felicidad no puede consistir más que en la integración, de la manera más completa posible, al mundo, i. e., en ampliar al máximo los límites de mi mundo. Es- 
tar en armonía con el mundo significa no tratar de alterarlo. Cada hecho es bienvenido y mientras menos rechacemos o intentemos evitar mayor será la armonía. Yo soy feliz cuando no tengo nada de que quejarme. De este modo, la felicidad real o completa de hecho equivale a la supresión total de deseo y a la aceptación irrestricta de lo que es el caso (puesto que de todos modos mi voluntad es impotente). El solipsismo también tiene su ética.

Para Russell, al contrario: la felicidad resulta de la acción que tiende a promover la vida en todos los "niveles" o "sectores" de la existencia humana. Él está consciente, desde luego, de la imposibilidad de probar que su concepción del hombre es verdadera y, por consiguiente, que la linea de conducta que él elige o proclama es objetivamente la mejor. Pero su idea parece ser que si aceptamos su interpretación de la naturaleza humana, podremos entonces elaborar un código moral acorde a dicha naturaleza, que sea útil y convincente, así como un sistema aceptable de ideales políticos. Para Russell, entonces, la búsqueda de la felicidad necesariamente compromete al individuo a la acción social, puesto que la vida espiritual activa es vida instintiva socializada.

Asimismo, la moralidad del hombre feliz wittgensteiniano resulta ser completamente diferente de la del hombre feliz russelliano. Russell enfatiza que "Si una concepción religiosa de la vida y del mundo ha de reconquistar alguna vez los pensamientos y los sentimientos de hombres y mujeres de mente libre, mucho de lo que estamos acostumbrados a asociar con la religión habrá de descartarse. El primero y más grande de los cambios que se requiere es el establecimiento de una moral de iniciativa, no de una moral de sumisión, de una moralidad de esperanza antes que de una de miedo, de una de cosas por hacer antes que de una de cosas que hay que dejar de hacer". ${ }^{40}$ Es evidente que no hay ninguna contradicción en Russell y que la resignación que ensalza y la iniciativa que promueve sólo aparentemente son incompatibles. La resignación es la actitud sana (racional) de un ser humano cuando se enfrente a lo irreversible, a lo inevitable, llámesele 'destino', 'designios de Dios' o del modo que sea. La iniciativa es la actitud del hombre completo cuando se enfrente a sí mismo, cuando, por así decirlo, se le ve o se ve a sí mismo “desde dentro". Por eso, a juicio de Russell, el hombre genuinamente religioso, todavía por producirse, "estará inspirado por una visión de lo que puede ser la vida humana y será feliz con la alegría de la creación, viviendo en un mundo amplio y libre, de iniciativa y esperanza". 41 La religión de este nuevo tipo de hombre, es decir, la nueva religión, lo hará “amar a la humanidad no por lo que ésta sea al ojo externo, sino por lo que la imaginación muestra que hay en ella por emerger. No estará presto a condenar, sino que alabará la vida,

40 B. Russell, Principles, p. 141.

41 Ibid., p. 141. 
el efecto rápido, la intuición creativa, mediante la cual el mundo puede crecer joven y hermoso y lleno de vigor". ${ }^{42}$ Esto constrasta notablemente con lo que serían las "acciones" del pálido hombre feliz wittgensteiniano, el cual sería más bien pasivo y trataría de vivir en la contemplación pura de lo que es eterno, indiferente ante sus configuraciones. Podría inclusive suceder que el hombre wittgensteiniano fuera socialmente útil, pero ello no pasaría de ser un afortunada casualidad, pues no sólo los vínculos causales son una ilusión sino que no hay nada tampoco en el Tractatus que pudiera operar como incentivo para la acción. Esto, evidentemente, acarrea consigo una concepción excesivamente estrecha y egocéntrica de la felicidad pero que, como sugerí más arriba, fluye de manera natural de su solipsismo. "Al mismo tiempo que la ausencia casi total de la noción de deber, se observa en la ética del primer Wittgenstein la ausencia característica de la referencia al otro. La reflexión sobre el problema moral es de tipo netamente solipsista y anti-histórico: '¿Qué me importa la historia? Mi mundo es el primero y el único' (Notebooks, p. 153)." ${ }^{43}$ Esto, a todas luces, es una "acusación" que no sería posible elevar en contra de Russell. Esta implicado, además, que toda clase de reflexión social y religiosa (en el sentido de Russell, es decir, "espiritual") está a priori excluida por y para Wittgenstein. Este admite, por lo tanto, que la felicidad es un estado al cual el individuo por sí solo puede acceder, en total abstracción de otros miembros de la comunidad. Esto es algo lógicamente excluído de la concepción russelliana de felicidad.

En un célebre pasaje del Treatise of Human Nature se nos dice que es lógicamente incorrecto pasar de oraciones evaluativas a oraciones descriptivas o, en una formulación más usual, de enunciados de hecho a enunciados de deber. Esta es la así llamada 'Guillotina de Hume'. Desde un punto de vista lógico, Hume se apunta aquí un éxito total e innegable. Wittgenstein por lo pronto acepta incondicionalmente el dictum humeano y lo asume literalmente y en toda su extensión. Para Wittgenstein, en efecto, los lenguajes éticos y descriptivo conforman dos áreas de discurso completamente diferentes e independientes. Así, pues, en este punto él está en total acuerdo con Hume. La desventaja que esto tiene en el caso del Tractatus es que convierte a toda clase de discurso político, religioso, moral, artístico, etc. en asignificativo y Wittgenstein, heroicamente, acepta las consecuencias de sus puntos de vista sobre el lenguaje, la lógica, etc. Por su parte, Russell parece estar en una posición desesperada, por contradictoria. Por un lado, leemos en Problems of Philosophy que "el desarrollo de este tema pertenece a la ética, en donde ha de establecerse la imposibilidad de deducir lo que debe ser a partir de lo que es"44 _lo cual

42 Ibidem.

43 J. Bouveresse, op. cit., pp. 100-101.

44 B. Russell, The Problems of Philosophy, Oxford University Press, Oxford, 1980, p. 43. 
constituye una adhesión explícita al principio de Hume- pero, por otro lado, Russell parece seguir a Hume sólo verbalmente, puesto que de su "teoría" de la naturaleza humana él intenta deducir principios morales. Esto requiere un mínimo de aclaración.

Lo primero que hay que hacer es observar que Russell se ubica desde el inicio en un terreno en el que no es la verdad o la falsedad "puras" lo que decide las cuestiones sino, más bien, lo que podría llamarse el 'grado de plausibilidad' de las construcciones que se ofrezcan. En casos como estos no estamos oponiendo teorías, sino concepciones (i.e., concepciones del Hombre) las cuáles desde el inicio incluyen, tácita o explícitamente, evaluaciones. Es claro entonces que las "explicaciones" que se puedan proporcionar no serán de orden causal (sería absurdo intentar elaborar leyes, por ejemplo). Por lo tanto, los criterios para decidir qué concepción habremos de adoptar serán diferentes de los que valen en ciencias como la física o la biología. Esto en sí mismo no implica que lo que se nos dice sea arbitrario o irracional. Así, el punto de vista de Russell parece ser que lo que tenemos que hacer es confrontar u oponer ideales incrustados en amplias concepciones del Hombre. Un test para seleccionar concepciones podría ser, por ejemplo, la coherencia. El papel que esas concepciones desempeñan es el de acomodar hechos, es decir, elaborar cuadros atractivos del ser humano y que deberían ser compatibles con los resultados obtenidos en las diversas ciencias. Es al integrar resultados de diferentes áreas en un cuerpo simple de doctrina que esas concepciones adquieren su poder explicativo. Al final, adoptaremos la explicación que nos resulte más satisfactoria y, junto con ella, el sistema moral y político que implique. Es evidente, sin embargo, que dichas concepciones no tienen, estrictamente hablando, un contenido puramente descriptivo, es decir, no son teorías científicas. Como dije, contienen, explícitamente o no, evaluaciones, pues no son otra cosa que interpretaciones de los fenómenos naturales. $\mathrm{Y}$, sin embargo, interpretaciones como la de Russell parecen ser sencillamente inevitables. Y si lo que he dicho es aceptable, entonces se puede ver que Russell, aunque comprometido con el dictum de Hume, está capacitado para eludir ciertas posibles consecuencias negativas que éste puede tener. En este punto, por lo tanto, la posición russelliana reviste una fuerza explicativa y práctica de la que carece el Tractatus.

Hay, para terminar, un punto que podría parecer de poca monta, pero que en mi opinión vale la pena considerar. Por alguna razón, Wittgenstein se nos aparece como más profundo. A primera vista, lo que Russell dice, cuando se le compara con lo que Wittgenstein dice, da la impresión de ser trivial o enteramente subjetivo o suena, en el mejor de los casos, como buena literatura. El origen de este juego de ilusiones se encuentra, por lo menos en parte, en cuestiones irrelevantes para el tema. Es el artilo de Wittgenstein lo que nos seduce y cautiva, así como su insistencia en hablar del modo prohibido y condenado por su propia doctrina. Es el hecho de que el misticismo de Wittgenstein per- 
tenece o parece pertenecer a la filosofía stricto sensu, en tanto que la de Russell tan sólo a la filosofía lato sensu, lo que genera el error y el acuerdo general sobre ese juicio. Pero es precisamente aquí que se vuelve aparente un rasgo de superioridad en el enfoque russelliano. Al igual que Wittgenstein, Russell piensa que nuestro lenguaje ( $y$ en general todo lenguaje descriptivo posible) no es apropiado o lo suficientemente fuerte para describir todo, pero él también parece pensar que lo que no puede describirse en esa clase de lenguaje puede ser expresado en uno diferente - y es claro que necesitamos un argumento para probar que no podemos en lo absoluto hablar de lo que queda fuera del alcance del lenguaje descriptivo. Por esta razón, Russell se siente forzado a arrancar desde otro punto de vista, acuñando para ello un lenguaje completamente nuevo. Russell parece pensar que sólo a través de una doctrina que no mantenga ninguna conexión esencial con la filosofía en sentido estricto o con la ciencia puede decirse algo significativo acerca del contenido de la vida y las creencias religiosas, políticas, estéticas, etc. Religión y ciencia no compiten, sino que se complementan. Si esto es válido, entonces hay que reconocer que Russell es a la vez coherente y profundo. La profundidad de su pensamiento, empero, se revela una vez más a través de un lenguaje simple, cuya estructura superficial no permite más que entrever algo de la riqueza de contenido que oculta. 